9 Kerr W'S. Effect of complete ureteric obstruction for one weck on opposite kidney function. F Appl Physiol 1954;6:762.

10 O'Reilly PH. Urinary stone disease. In: Obstructive uropathy. Berlin: SpringerVerlag, 1986:103-4

11 Usberti M, Mileti M, Maiorca R. The effect of indomethacin on renal function. Mineria Nefrol 1975;22:299-303.

12 Ferrie BG, Glen ES, Hunter B. Longterm urethral catheter drainage. BMF 1979;ii:1046-7.

13 McGuire EJ. Neuromuscular dysfunction of the lower urinary tract. In: Walsh PC, Gittes RF, Perlmutter AD, Stamey TA, eds. Campbell's urologv. 5th ed. Philadelphia: Saunders, 1986:616-38.

14 Kennedy AP, Brocklehurst JC. The nursing management of patients with long term indwelling catheters. $\mathcal{F}$ Adv Nursing 1982;7:411-7.

15 Brocklehurst JC, Brocklehurst $S$. The management of indwelling catheters. Brf Urol 1978;50:102-5.

16 Kennedy AP, Brocklehurst JC, Lye MDW. Factors related to the problems of long term catheterisation. F Adv Nursing 1983;8:207-12.

17 Blandy JP. How o cathererise the bladder. Br F Hosp Med 1981-26:58-60.

18 Tiptaft RC. The urinary bladder. In: Harding Rains AJ, Mann CV, eds. Bailey and Love's shorl practice of surgery. 20th ed. London: Lewis, 1986:1254-97. 9 Blandy JP. The prostate gland. In: Lecture note's on urologv. (Oxford: Blackwell. 1977:192-207.

20 Brocklehurst JC. The genitourinary system - the bladder. In: Textbook of geriatric medicine and gerontologv. Edinburgh: (Churchill Livingstone, 1985 $626-47$

21 Philip PF. Prostate and seminal vesicles. In: Harding Rains AJ, Ritchic HD, ds. Bailey and Love's short practice of surgerv. 7th ed. London: Lewis, 1975:1187-208

22 George NJR, O'Reilly PH, Barnard RJ, Blacklock NJ. Practical managemen of patients with dilated upper tracts and chronic retention of urine. Brf Urol 1984:56:9-12.

23 Jones DA, O'Reilly PH, (jeorge NJR, Barnard RJ. Reversible hypertension associated with unrecognised high pressure chronic retention of urine. Lancet 1987:i:1052-4.

24 Peterson LJ, Yarger RF, Schooken DD, Glenn JF, Post obstructive diuresis a varied syndrome. 7 Lrol 1975;113:190-4.

25 Lawrence WT. Urinary retention. Surgery 1990;77:1838-43.

\title{
St Mary's Hospital, Isle of Wight: a suitable background for caring
}

\author{
Richard Burton
}

Nine years ago we participated in a low energy hospital study for the Department of Health and Social Services on "low energy nucleus" and were subsequently commissioned to design the first low energy hospital. Now the 191 bed St Mary's Hospital on the Isle of Wight is ready for its first patients and will be formally opened next spring. It is appropriate that this major energy saving initiative should have come from the Department of Health because in the late 1970s the NHS used $1 \%$ of all energy in Britain. The initiative was timely for two reasons: firstly, the urgent need, of which we are now all aware, to halt both the depletion of the planet's resources and the consequent pollution from exhaust products; and, secondly (as readers of this journal well know), the desperate need for doctors and nurses to work in a good environment for healing.

\section{The challenge}

Our initial study in 1981 was to see if a new "nucleus" hospital could have its energy expenditure cut by half - a challenge tailor made for our practice, as we are specialists in energy conservation. In the same year, during a three day working session with representatives of the Department of Health, the Wessex Regional Hospital Authority, the local district health authority, and our specialist consultants, we outlined

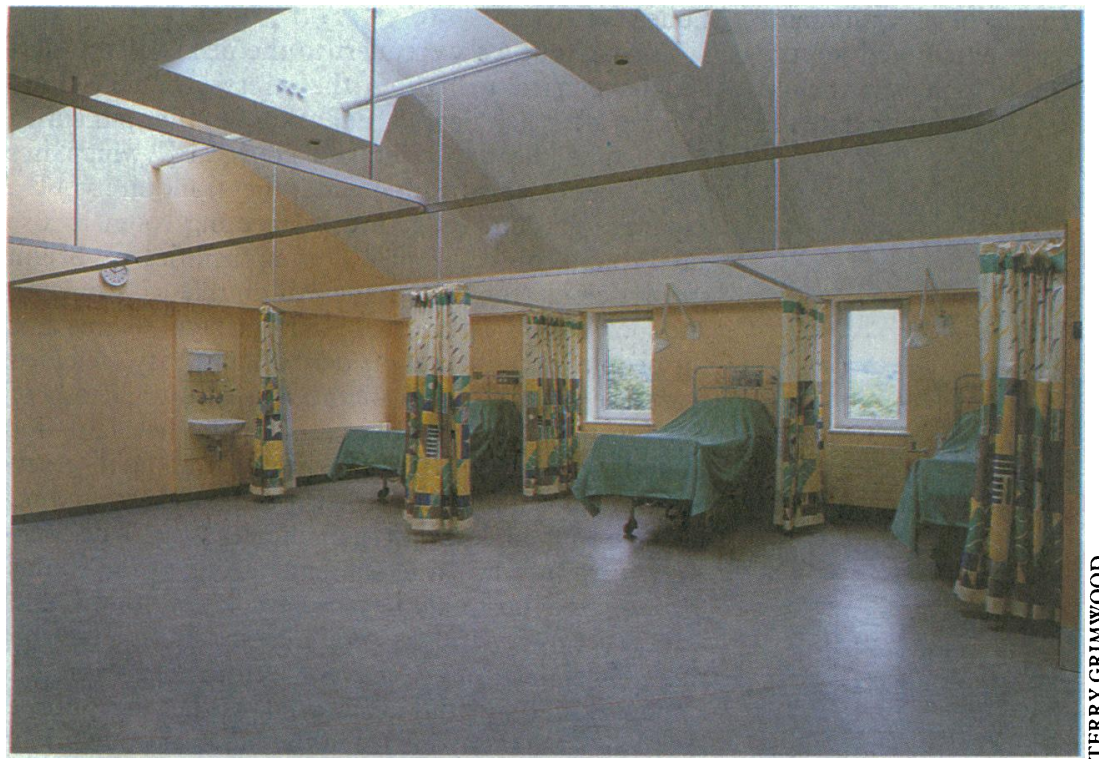

FIG 1-Wards are light and airy, with interesting ceilings and view windows. the way the hospital should be. In 1982 we were asked for proposals for incorporating art and craft into the hospital-again something to which our practice has been committed. We have always incorporated art and craft into our design and have also made it a practice to donate a tree for the landscaping of our buildings.

From the start I took very seriously a study that seemed to confirm what most of us instinctively know: that harmonious surroundings-natural and man made-actually speed the healing process.' I had a further, personal interest in hospital design. While an NHS patient in the early 1970s I thought a great deal about how to make a hospital more human and congenial. For instance, like every patient before me, I'd spent a lot of time lying in bed and staring at the ceiling. So I knew how important ceiling shapes and materials are to patients and how boring ceilings normally are. The ceiling shapes in St Mary's are complex (fig 1); their design is one of the bonuses of the energy conservation. In due course mobiles will be added to provide an escape route for the patient's imagination from the confines of bed and ward.

We wanted to make St Mary's a place in which not only patients but also the public and the staff would enjoy the environment. The staff was of great importance because they have to be in the hospital throughout the year, often working under great stress. If they are happy, patients will have a better quality of care. And if the environment is visually interesting, even uplifting, everyone's mood will improve, and patients will have opportunities to divert their minds from their illnesses.

\section{Energy savings}

Experience had shown us that energy saving can result not in austerities but in benefits of both aesthetics and comfort. For instance, when we analysed the energy use in a nucleus hospital we found that $22 \%$ was used in the kitchen. Efforts to keep the cooks cool were being directed at pushing the heat out of the kitchen into the surrounding air, as anyone who has walked past a hospital kitchen and suffered a blast of hot air well knows. Recycling that heat for use elsewhere brought the bonus of a cooler kitchen and insulated fittings. Another example: we knew that if we could design a naturally lit hospital that too would effectively cut energy bills, because electricity is such a high cost fuel-and at the same time the natural light would lift the spirits of everyone in the building.

In fact the chief feature of St Mary's is that it is a light building, both literally and in mood. The lightness begins outside, with the high tech stainless steel 


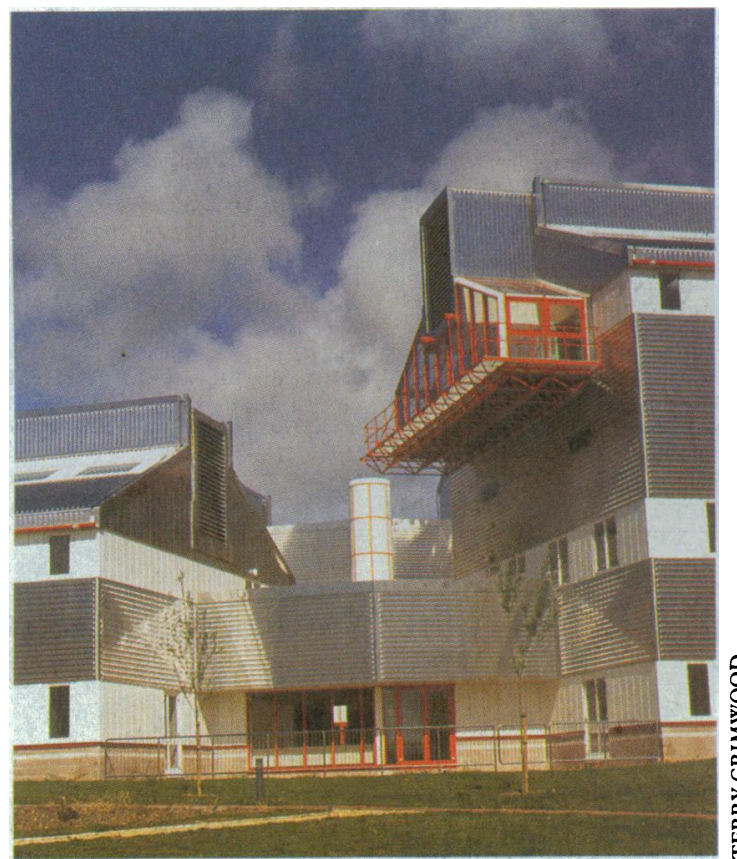

FIG 2-Stainless steel cladding reflects light and aids energy conservation. Each ward has its conservatory looking down on the garden and its lake

cladding that has attracted so much comment (fig 2). The feedback to us is that the longer people look at it the more they seem to like it: like all unfamiliar design, it needs to become familiar before people can have a direct and genuine response. Also, the planting needs time to establish itself. The stainless steel bounces daylight back into the building and reflects the heat outwards, keeping the hospital cool on hot days. The aesthetic bonus lies in the reflections on its surfaces-always changing in the light, reflecting and patterning everything from sunsets to storm clouds.

Inside the hospital, however, the "feel" is deliberately human and efficient. Some of the energy measures are common sense-low energy lighting, larger radiators at lower temperatures, good insulation, double glazing, and, in summer, opening windows. The energy distribution is in a floor separate from the main hospital areas : like arteries and veins they do not meet (fig 3). The to and fro of supply, and the recovered energy from incinerators, generator engines, air treatment-even washing up water-is funnelled along unseen pipes and stored in containers in the energy centre for later use. Dedicated service space allows for easy access for maintenance of all equipment. The hidden energy system has contributed to the interest of ward ceilings: they are as high as in the old hospitals but curve lower in places to accommodate the

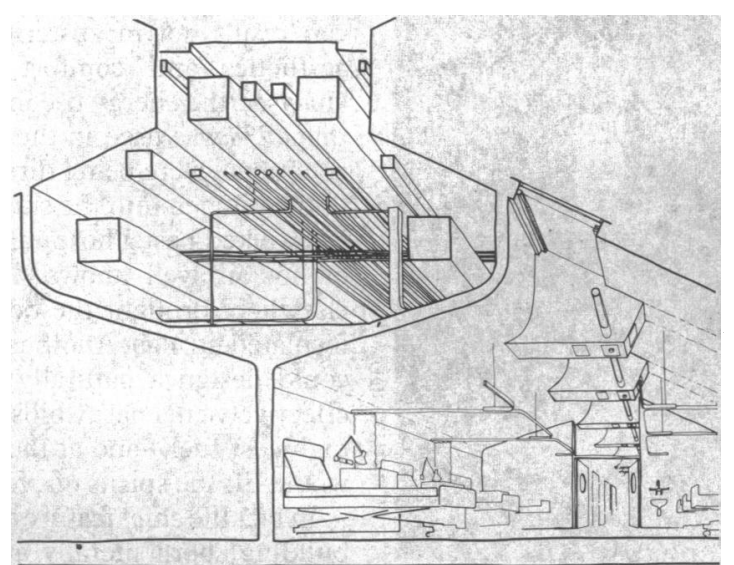

FIG 3-Cross section of a ward showing the hidden energy system maintenance corridors behind. The wards are light and airy, nothing like the shallow boxes of my own experience, and people working in them have commented favourably on their height and character.

Our use of natural light was another bonus of energy saving. Not only is it useful in diagnosis, it is also becoming clear how important the full spectrum of light is for ordinary living - even more so, therefore, for healing. Gloomy, dull rooms seem to depress people, and levels of natural light in buildings have generally been far too low. Daylight inside any building makes people feel more positive and more in touch with the world outside. In St Mary's the combination of light, air, and visual interest (both the landscape and the works of art) should have this effect. Every room in the hospital in which people spend any time has natural light and views. In the operating theatres, too, we have managed a chink of view to remind the staff working in there of the weather outside. The only exceptions are areas such as the recovery rooms and intensive care units, where light is deliberately reduced.

\section{Wards and themes}

The children's wards are on the ground floor to allow for a play area (there are also parents' rooms), but all the other wards are on the second and top floors, with view windows and sloping ceilings with roof lights. The visual interest is sustained by specially designed curtains and by pin boards on to which patients can put cards, letters, family photographs. Very ill patients want little stimulation, but later, as the patient gets stronger, he or she will be able to sit in the conservatories at the end of each ward, which look down on the garden with its lake and island. The wards will be quiet places. Mobile and recovering patients will interact more and more with the life of the hospital, in its streets and foyers and shops, where we have also designed spaces for activities such as live music, poetry, and storytelling.

The theme of the hospital is the healing power of water, and right through the hospital we have replaced institutional colours with shades and patterns that suggest the sea and sun. There are wave patterns on the entrance linoleum. Portholes connect the children's wards, which have stepping stones to the playroom, and a wavy wall is decorated as a seascape at the entrance. The landscaping continues through the hospital: a series of nine courtyards are really outside rooms, each with its own design, colour and atmosphere, such as the "dry river bed" court and the "water" court designed by students at the Royal College of Art.

Throughout we were alert to the needs of the staff and have tried to lighten the stresses of constantly looking after sick people. For example, the staff coffee area fronts the dry river bed courtyard, which has reeds, pebbles, sunshine, and the tranquillity of a Japanese garden. A lecture or meeting room is also sited round this courtyard. Dining facilities are bright and spacious (the restaurant can double as a theatre) and look out on yet another court garden. A table area for people on night duty is deliberately cosy, shielded from the empty spaces of the restaurant. Details of the finishing were all discussed with the staff-for example, in the operating theatre the light green terrazzo floor tiling and darker green tiles surrounding the operating tables were their choice. We also deliberately introduced a large staircase as one of the routes through the hospital, because we know how much informal contact and hospital business takes place on the main stairs. And we have placed the chapel not in some secluded spot but in one of the busiest parts of the hospital, so that anyone using the main lifts need only to open a door to find themselves in this quiet space. 


\section{Landscape and art}

The gardens, which we hope will help staff unwind as much as patients, were designed by James Hope. The lake, in homage to Monet's "waterlily" garden, has a bridge, an island, walkways, secluded areas, a summer house, and wildfowl. Landscape is theatre: there is a difference, particularly to recovering people, between a static view and a view with life and movement in it. Stocking the lake with wildfowl and fish has been a local initiative, and we are delighted that the health authority has agreed that the area can be open to the public.

The landscaping is as much part of the arts project as the design for live performances of all kinds and the works of art themselves. Art is the other healing aspect of the hospital, complementing the medical. The key pieces of the art collection for stage one are already made - the large tapestry of the island, by Candice Bahuth, made up of panels worked by hospital staff, patients, and community groups (even someone in our office), hangs on a wall of the main stair, and a huge ceramic mural is to be installed on a subsidiary staircase. In time each ward will have its own entrance mural, and the art collection will grow: there are places for another 250 pieces of art, including a sculpture park in the landscape. My hope is that there will eventually be some work in every space in the hospital, including the cleaners' cupboards. And of course the art collection is for the staff as much as anyone else; staff members will be able to choose the works they want in their rooms, rather than having to live with the choice of others. Guy Eades, the full time arts coordinator, is an important member of the hospital staff and works with the doctors, nurses, and administrators. Some $£ 250000$ has been raised so far. The arts project could greatly benefit over the years from patients and their families wishing to express their gratitude to hospital and staff: plant a tree to celebrate a new baby, for instance, or help buy a mobile or painting for the collection.

Sponsorship and generous community involvement have been important elements in the fundraising for the arts project. Leading Leisure sponsored the lake project, Sealink the main mural, Southern Arts the ceramic on the staircase. But no money that would otherwise have gone to a scanner or kidney machine was diverted to the arts programme, which was sponsored from sources that would not otherwise have been involved-such as the Gulbenkian Foundation, which provided money for the project. In parallel with the arts programme appeal there was also a very successful appeal for a scanner; the one fundraising scheme has not inhibited the other.

\section{Hospitals for the future}

St Mary's is, to me, a pathfinder hospital for the ' 90 s. Others clearly see it that way too-it has already attracted professional visitors from all over the world. But I also see it as a beginning. Modern hospitals in cities are the largest community buildings we have, and part of the largest industry in Europe. They are usually antiquated, they waste much energy, they have, and will increasingly have, huge staffing problems because of transport and housing that is inadequate, outdated, and depressing. New dimensions must come into play when we reconstitute our city hospitals. They must accommodate themselves to the requirements of technology and biomedicine, to the global requirements of sensible energy use, and to the human requirements of the healing process - which means they must look after their staff as well as their patients. We may need to create a new model on the lines of a hospital town in the middle of our major cities, just as there were once university towns. It would be a multifunctional unit with hospital buildings, educational establishments, housing, commercial facilities, and related services and industries - but all essentially part of the community. This may be where the best future lies. In the same way as I once lay in an NHS bed thinking about hospital design and have incorporated those ideas within St Mary's, I have now seen some of the problems faced by our urban hospitals and know that the formula worked out at St Mary's could help.

1 Ulrich R. View through a window may influence recovery in surgery. Science 1984;224:420-1.

\title{
Are orthopaedic surgeons really gorillas?
}

\author{
John S Fox, Gordon R Bell, Patrick J Sweeney
}

\section{Departments of \\ Orthopaedic Surgery and \\ Neurology, Cleveland \\ Clinic Foundation, \\ Cleveland, Ohio \\ 44195-5001, United States \\ John S Fox, MD, chief \\ orthopaedic resident \\ Gordon R Bell, MD, staff \\ surgeon \\ Patrick J Sweeney, MD, staff neurologist}

Correspondence to: Dr Bell.
Critical comparison between orthopaedic and general surgeons is woefully absent in scientific publications, leading to speculation, innuendo, and myth. This often results in derogatory remarks about one of these two categories. Previous reports in the $B M F$ have lent some credence to the long held traditions and popular myths that the orthopaedic surgeon is a man of enormous build and great strength, if perhaps a little slow ${ }^{1}$; that orthopaedic surgery requires brute force, ignorance, and a perception of pain $^{2}$; and that orthopaedic surgeons are somewhat prone to injury. ${ }^{3}$

An anthropomorphic connection between orthopaedic surgeons and gorillas was implied by the results of a study in the United Kingdom, which showed that orthopaedic surgeons' mean glove size was $7 \cdot 6$ and general surgeons' was $7 \cdot 4 .^{1}$ This study was flawed from a scientific and interpretive aspect. Firstly, the study failed to consider that including female orthopaedic or general surgeons would alter the mean glove size in their sample. Secondly, there was no information on whether orthopaedic and general surgical trainees (residents) were included. Thirdly, there was no data on the glove size of actual gorillas. In addition, the study was not prospective or double blind and did not include a crossover. There was no disclaimer that funds were not received from any interested party. At best, results could only support the contention that orthopaedic surgeons are bigger gorillas than are general surgeons. To correct for these flaws we undertook a randomised double blind study.

\section{Subjects, methods, and results}

An unbiased and totally ethical letter was submitted to the theatre "executive nurse" in major hospitals across the United States. The innermost glove size and the sex of orthopaedic surgeons and residents and of general surgeons and residents were recorded. As an adjunct study glove sizes of locally available gorillas were measured.

Glove sizes were recorded from 483 surgeons -217 orthopaedic and 266 general. In the orthopaedic group there were 97 staff surgeons and 120 residents, including four female staff surgeons and four female 